\title{
Numerical-experimental analysis of a modified G- BOP test to evaluate cracks in weld beads in thin sheets
}

\section{Saulo Moretti Araújo Duarte}

Universidade Federal da Paraiba

Heitor Silva Pereira Abdias ( $\nabla$ abdiasheitor@gmail.com )

Universidade Federal da Paraiba https://orcid.org/0000-0002-7578-2954

José Hilton Ferreira da Silva

Universidade Federal da Paraiba

Kelly Cristiane Gomes

Universidade Federal da Paraiba

\section{Research Article}

Keywords: hydrogen-induced cracking, finite element method, thermal cycle, welding residual stresses

Posted Date: April 30th, 2021

DOI: https://doi.org/10.21203/rs.3.rs-452945/v1

License: (c) (i) This work is licensed under a Creative Commons Attribution 4.0 International License. Read Full License

Version of Record: A version of this preprint was published at The International Journal of Advanced Manufacturing Technology on October 1st, 2021. See the published version at https://doi.org/10.1007/s00170-021-08121-z. 


\title{
Numerical-experimental analysis of a modified G-BOP test to evaluate cracks in weld beads in thin sheets
}

\author{
Saulo Moretti Araújo Duarte · Heitor Abdias da Silva Pereira · José Hilton Ferreira \\ da Silva · Kelly Cristiane Gomes
}

Received: date / Accepted: date

\begin{abstract}
One of the most critical problems related to welding is the occurrence of Hydrogen-Induced Cracking (HIC), and despite all the efforts made to mitigate this defect, it remains present in modern welding industry. Although the Gapped Bead-on-Plate (G-BOP) test is one of the most practical methods for assessing susceptibility to HIC, its application is restricted by the fact that it employs a thick plate as the base metal. Considering that many materials, such as the High-Strength-Low-Alloy (HSLA) steels, are difficult to find commercially in the required thickness, and also the fundamental need to appropriately represent the relationship between base and weld metals, da Silva, Fals and Trevisan [7] developed a modified G-BOP test that uses a thinner sheet as the base metal. Thus, the present paper aims to evaluate the ability of the Finite Element Method (FEM) to represent the thermomechanical aspects of the G-BOP test, and then to analyze the modified version proposed by [7] using a numerical-experimental approach with the FEM as a support tool in the investigation of HIC phenomena. The results, in addition to consolidating the modified version of
\end{abstract}

Saulo Moretti Araújo Duarte

Campus I - Lot. Cidade Universitaria, João Pessoa - PB, 58033-455 ORCID: 0000-0001-6660-4550

Heitor Abdias da Silva Pereira

Campus I - Lot. Cidade Universitaria, João Pessoa - PB, 58033-455

Tel.: +55-83-982190671

ORCID: 0000-0002-7578-2954

E-mail: abdiasheitor@gmail.com

José Hilton Ferreira da Silva

Campus I - Lot. Cidade Universitaria, João Pessoa - PB, 58033-455 ORCID:0000-0001-8966-7896

Kelly Cristiane Gomes

Campus I - Lot. Cidade Universitaria, João Pessoa - PB, 58033-455 ORCID:0000-0002-0255-8740 the test, corroborate the FEM as an important ally in HIC studies.

Keywords hydrogen-induced cracking $\cdot$ finite element method $\cdot$ thermal cycle $\cdot$ welding residual stresses

\section{Introduction}

The development of the so-called High-Strength-Low-Alloy steels (HSLA) allowed, among many benefits, the fabrication of components with increasingly smaller thicknesses, consequently lighter and more slender, but retaining the capability to appropriately resist the service loads. For such characteristics, these steels, particularly the API 5L Class X standard, find great relevance in the oil and gas industry.

Nonetheless, the welding of such materials is related to various challenges, especially Hydrogen-Induced Cracking (HIC), also known as Delayed Cracking or Cold Cracking, because it generally occurs many hours, days, or even weeks after the welding, at room temperature. Although it is one of the most studied defects related to welding, it is one of the less comprehended [1]. However, it is consent that three fundamental elements must be present for HIC to occur: hydrogen dissolved in the weld bead, susceptible material microstructure, and tensile stresses acting on the welded element [2].

The hydrogen will always be present in welds, whether due to the flow used by the welding process, the atmosphere itself, the electrode coating, or from contamination on the workpiece surface. Its dissolved molecules in the weld bead present a tendency to accumulate in the existent crystalline defects in brittle microstructures such as martensite and bainite, very common in welded components [3]. Regarding the tensile stresses, even though they may arise from mechanical solicitations in service, welding residual stresses are also likely to cause the problem as they are the first to act in the 
component after the welding $[4,5]$, therefore, playing an important role in the HIC.

As for the need to evaluate the susceptibility of a welded joint to HIC, many tests have been developed, but, for its versatility and simplicity in quantifying the HIC effect, the Gapped Bead-on-Plate test (G-BOP), proposed by Graville and McParlan [6] in 1974, is one of most employed ones. Even though its benefits are many, the use of plates with $50.8 \mathrm{~mm}$ (2") of thickness as Base Metal (BM) are a considerable disadvantage, because the Weld Metal (WM) needs to be evaluated with the BM for which its application is recommended, and many materials, such the HSLA ones, are most commonly found in considerably smaller thicknesses to be commercially viable[7]. Then, da Silva, Fals and Trevisan [7] proposed a modified G-BOP test configuration to be applied for small thickness HSLA steels as BM, to properly investigate its indicated WM susceptibility to HIC.

The improvement of computational capabilities has made numerical methods, in particular the Finite Element Method (FEM), a strong ally for engineers to understand phenomena of various engineering areas. It has been successfully applied in the simulation of welding regarding its thermal [8-11] and structural [12-16] aspects. Therefore, the present paper aims to apply this tool, using the commercial software $\mathrm{ANSYS}^{\circledR}$, in the evaluation of the modified G-BOP test through a numerical-experimental analysis of three study cases: case 1, a standard G-BOP test with AISI 1020 steel as BM; case 2, a modified G-BOP test with AISI 1020 as small thickness BM; and case 3, a modified G-BOP test with the API 5L X70 HSLA steel as small thickness BM. As cases 1 and 2 use the same material as BM, they allow to assessing the ability of the modified G-BOP test to maintain the characteristics of the standard test. And case 3 is the application of the obtained numerical results following the experimental data in a practical case, providing relevant information in the matter of HIC and its structural aspect.

\section{Theoretical and practical review}

\subsection{Hydrogen-Induced Cracking}

According to Plessis and Maoref [3], the HIC dynamic starts with the atoms, ions, and molecules of hydrogen present in the atmosphere, material surface, gas, or material flux involved in the welding, dissolving into the weld bead during the operation.

During the subsequent cooling and solidification, the WM becomes supersaturated with hydrogen, which tends to migrate to the Heat Affected Zone (HAZ) seeking to balance the dilution. If the HAZ microstructure is austenitic, which can hold much more hydrogen, it will be diffused across its fusion line. Otherwise, it will remain in the WM. Independently of the region in which the hydrogen is present, during the quick cooling after welding, brittle microstructures, such as martensite and bainite, appear, which makes the trapped hydrogen be in a high level of energy. Then, this hydrogen migrates for the defects and discontinuities in the crystalline structure, being accumulated in these "traps".

From that point on, the welding residual stresses act in the traps, already weakened by the presence of the high state energy hydrogen, starting the crack formation. To decrease its energy state, the hydrogen is then released in the crack, accelerating its growth to points far from the traps, and consolidating the HIC.

\subsection{Standard and modified G-BOP test}

Developed by Graville and McParlan [6] em 1974, the GBOP test has the purpose of evaluating the HIC susceptibility in WM in welded structural steel and consists basically of a WM deposition across a gap typically of $0.75-1 \mathrm{~mm}$ in length and $100 \mathrm{~mm}$ wide between two thick blocks of $100 \mathrm{~mm}$ $\mathrm{x} 125 \mathrm{~mm} \times 50,8 \mathrm{~mm}$. Figure 1 shows the schematic representation of this test.

After the welding, and being held in position by the $\mathrm{C}$ clamp for at least 48 hours, the weld in the gap vicinity is heated to cause a heat tint in the affected area, highlighting the HIC $[7,17]$. After 24 hours more, the specimen is broken in the Gap portion, and its cross-section is analyzed, with the results being presented as the percentage of area affected by HIC. The geometrical modification proposed by da Silva, Fals and Trevisan [7] is also displayed in Figure 1 , with emphasis on the complement plates under the sheets acting as BM so the whole specimen reaches the standard test thickness, and the $12.5 \mathrm{~mm}$ bolts attaching the assembly. The standard test dynamic, as described above, are the same for the modified test.

For the appropriated characterization of the phenomenon, it is important that the appropriated WM for a given BM is employed, because the dilution effects between them are taken into account [7]. Also, the establishment of the welding residual stresses, crucial to the occurrence of HIC, depends, beyond the geometry and restraining conditions, on the thermomechanical properties of the materials [8-16].

\subsection{Welding simulation by FEM}

The correct characterization of the multiphysics is the first key point to attend in the simulation of welding processes. There is the thermal aspect, inherent to the localized heating from the electric arc and its propagation to the other parts of the component and the environment; the microstructural aspect, related to the microstructural changes in the material during welding; and the structural aspect, represented by the stresses related to the deformations in the component during 

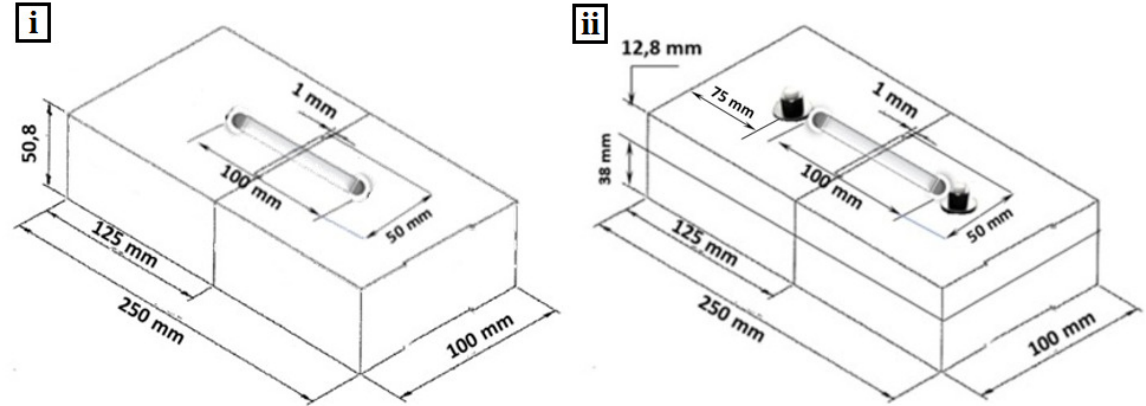

Fig. 1 Standard (i) and Modified (ii) G-BOP test specimen.
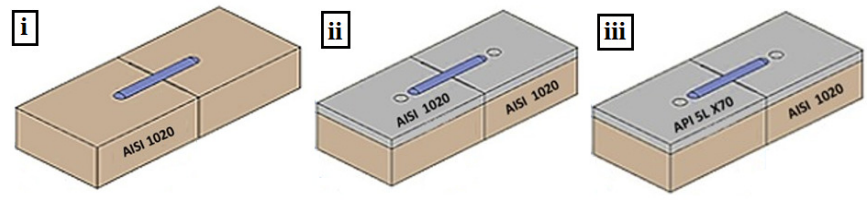

Fig. 2 Schematic representation of the cases 1 (i), 2 (ii) and 3 (iii).

the thermal cycle, which remain even after the whole process takes place, and are, therefore, called "residual stresses" [12-16].

The second central point is the appropriated definition of the simulation goals, which allows applying the most indicated approach regarding the relationship between the physics: the one-way or two-way coupling. In the first one, the simulations are carried out sequentially for each physic, according to the dependency of results, which has to be very strong in one way, and weak in the other. In the second one, only one simulation, with degrees of freedom in the element nodes
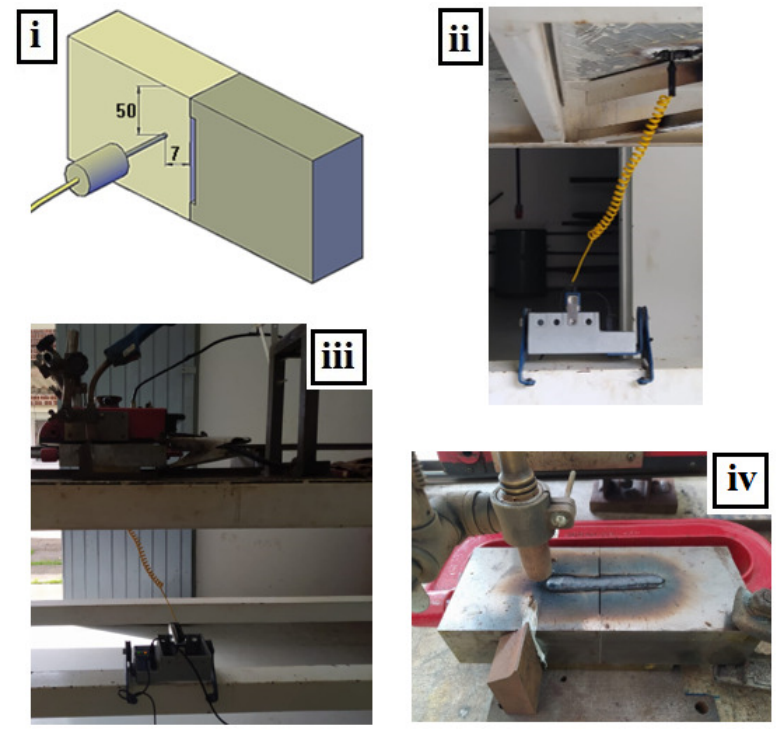

Fig. 3 Position of the thermocouple (i), real measuring device arrangement (ii), automatic welding mechanism (iii) and welded specimen (iv). involving all the physics, is performed, being indicated to a strong dependency in all ways between the physics.

Finally, the appropriated representation of geometry, materials, boundary, and loading conditions must be taken into account. The CAD geometry must include all essential parts in the workpiece, which is the simulation domain, and a FEM mesh with enough refinement to capture results convergence. The materials must have their thermomechanical properties well defined, with their non-linearities in temperature and deformation, making possible an accurate numerical solution of the differential equations defining the problem. The boundary conditions are represented in the thermal and structural aspects, respectively, by heat transfer modes in the workpiece external surfaces and its imposed mechanical restrictions to displacement. The loads are heat source model in the thermal analysis, representing the electric arc, and node displacement, calculated by the FEM from the material properties together with thermal results, for the structural analysis.

\section{Materials and methods}

\subsection{Experimental analysis}

To investigate the behavior of the modified G-BOP specimens, three different analysis have been made: case 1, applying the standard G-BOP test with AISI 1020 steel plates; the modified G-BOP test in case 2, with AISI 1020 steel in both small thickness BM and complement blocks; and case 3 , the same as case 2, but with API 5L X70 as small thick-
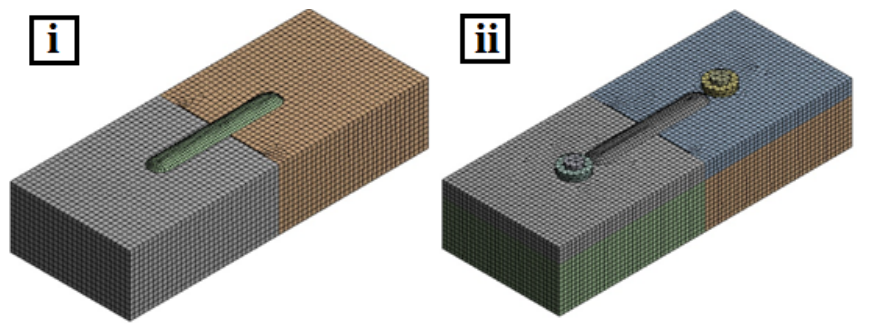

Fig. 4 FEM mesh for standard (i) and modified (ii) G-BOP specimens. 
ness BM. Figure 2 shows the schematic representation of the three cases and the real test specimens. For cases 2 and 3, the contact surfaces between the BM and complement block were worked out until they reached a roughness of $0.65 \mu \mathrm{m}$, and torque of $821 \mathrm{Nm}$ was applied in the $12.5 \mathrm{~mm}$ diameter bolts assembly, following the manufacturer's manuals.

For each case, an automatic FCAW was performed according to the test steps described in [6] and, for the modified cases, in [7], with the welding parameters shown in Table 1.

Table 1 Welding parameters.

\begin{tabular}{llll}
\hline Voltage $(\mathrm{V})$ & 28 & Wire feed speed $(\mathrm{m} / \mathrm{mi})$ & 7 \\
\hline Current $(A)$ & 211 & CTWD $(\mathrm{mm})$ & 19 \\
\hline Velocity $(\mathrm{mm} / \mathrm{min})$ & 223,6 & Gas flow $(\mathrm{l} / \mathrm{min})$ & 15 \\
\hline
\end{tabular}

The thermal cycle in the specimens was measured during and after welding, with a $\mathrm{K}$ type thermocouple, positioned at $1.5 \mathrm{~mm}$ under the weld bead, as displayed in Figure 3, which also shows images of the welding apparatus and procedure.

After the determined time interval, the components were submitted to heating to highlight HIC areas, broken through a bending moment, and the HIC affected areas were measured.

\subsection{Numerical analysis}

In the present paper, FEM simulations were carried out in the ANSYS ${ }^{\circledR}$ commercial software, and aimed to obtain the thermal cycle in a specific position in the standard and modified G-BOP specimen. The numerical results may then be compared with the experimental results for the thermal cycle in the same position, making it possible to validate the modeling for the referred application. Afterward, the FEM is used to estimate the level and distribution of the welding residual stresses in the weld bead of the G-BOP specimens, an essential condition to the HIC phenomenon. Figure 4 shows the CAD model with its respective FEM mesh, with a refinement option applied in the weld bead, and verified in convergence tests. For cases 2 and 3, both with modified specimens, but with different materials for the BM, the same mesh was applied.

The multiphysics approach was the one-way coupling. Such choice is explained by the strong dependency that exists on the welding residual stresses concerning the thermal cycle, with minimal reverse dependency. The microstructural effects are represented by the accurate description of the thermomechanical properties and its variations with temperature, as illustrated in Figure 5 for the AISI 1020 steel [18], and Figure 6 for the API 5L X70 [19] fundamentally
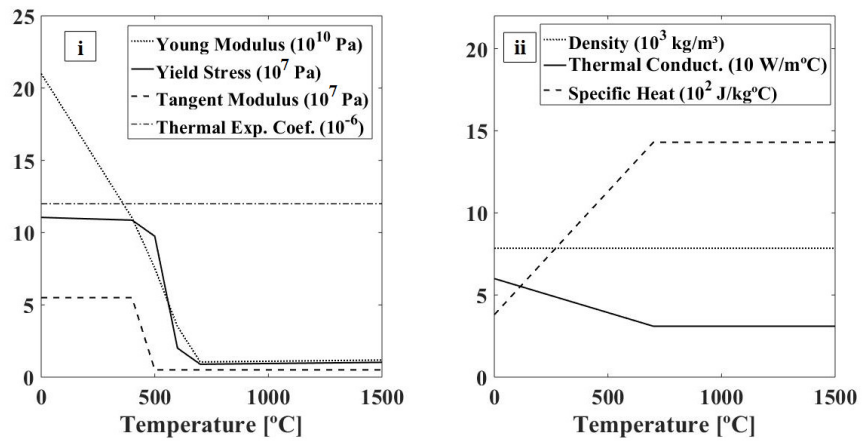

Fig. 5 AISI 1020 steel thermal (i) and mechanical (ii) properties [18]
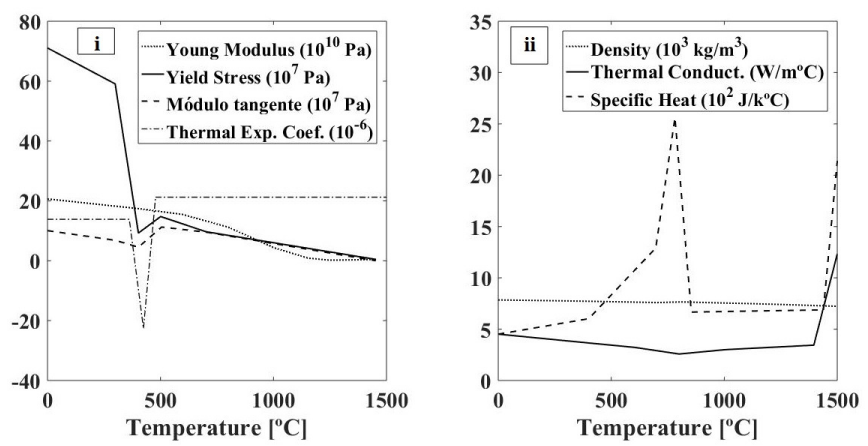

Fig. 6 API 5L X70 thermal (i) and mechanical (ii) properties [19].

defined by microstructural transformations. This approach was used in many other studies [12-16]. The WM was the AWS E81T1 flux-cored wire, suitable for the welding of API 5L X70 steel. Its mechanical properties were implemented according to the described by its manufacturer, with a yield strength of $566 \mathrm{MPa}$, an ultimate strength of $635 \mathrm{MPa}$, and an elongation of $22 \%$, and the thermal properties were replicated from API 5L X70 steel.

In the thermal analysis, the heat source model utilized was the hemispheric [20], implementing the welding parameters of Table 1, an efficiency of 0.75 and geometric parameters gathered by measurements of the weld bead in the experimental analysis [4]. Boundary conditions were convection and radiation applied to the external surfaces of the specimen, except for those restrained by the C-clamp. Convective coefficient $h$ and emissivity $\varepsilon$ were, respectively, 25 $\mathrm{W} / \mathrm{mm}^{2} \mathrm{~K}$ and 0.5 , following the described by [21].

The referred assembling torque of $821 \mathrm{Nm}$ in cases 2 and 3 , according to the considerations and the proposed equation in [22], induces a load of $73.6 \mathrm{kN}$, from which $50 \%$ are dedicated to overcoming the friction on the nut-specimen interface, $40 \%$ for the friction on the bolt fillets, and $10 \%$ produces actual tensile in the bolt, which means an active load of $7.36 \mathrm{kN}$. It is important to point out that this active load produces compressive stress of $0.6 \mathrm{MPa}$ in the contact area between BM and complement plate. Also, together with the indicated roughness of $0.65 \mu \mathrm{m}$, microhardness measurements of $115 \mathrm{HV}$ for AISI 1020 steel and $205 \mathrm{HV}$ for 
API 5L X70, and the equation proposed in [23], the thermal contact conductance of $2,06 \mathrm{~kW} / \mathrm{mm}^{2} \mathrm{~K}$ was obtained and implemented in the software.

In the structural analysis, the specimens were restrained to any free body movement, the bolts preloads were applied, as well as the nodal displacements from the thermal analysis as body loads.

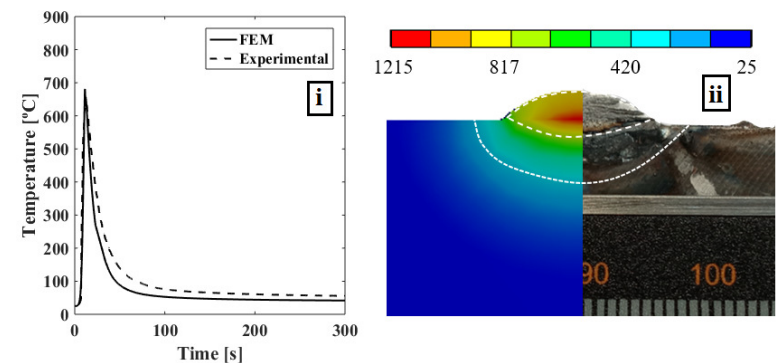

Fig. 7 Numerical-experimental comparison of the thermal cycle in the thermocouple position (i) and of the weld bead cross-section (ii) for standard G-BOP test in case 1 .

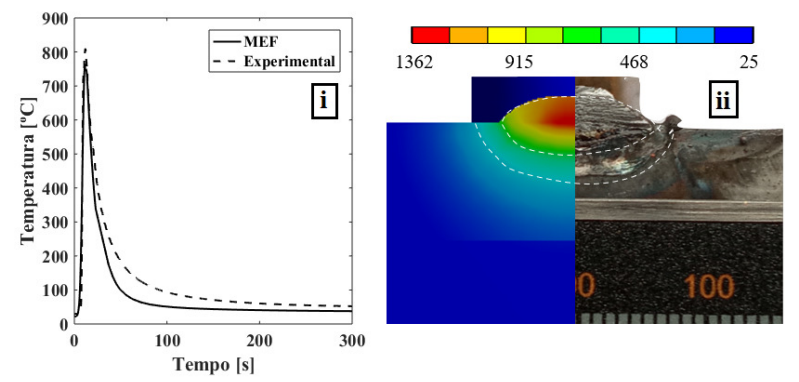

Fig. 8 Numerical-experimental comparison of the thermal cycle in the thermocouple position (i) and of the weld bead cross-section (ii) for the modified G-BOP test in case 2 .

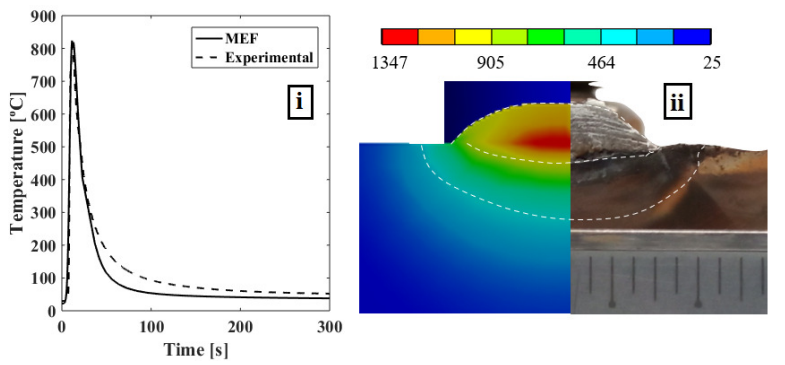

Fig. 9 Numerical-experimental comparison of the thermal cycle in the thermocouple position (i) and of the weld bead cross-section (ii) for modified G-BOP test in case 3.

\section{Results and discussion}

\subsection{Thermal cycle}

The thermal cycles obtained in the experimental analysis using the thermocouple, as described by Figure 3, is presented with its numerical counterparts in Figures 7, 8 and 9.

It is possible to observe the good agreement between experimental and numerical analysis results regarding the thermal aspect of welding. The higher discrepancy between peak temperatures is in case 2, which has AISI 1020 steel as $\mathrm{BM}$ and complement block in the modified G-BOP test, with a deviation of $4.9 \%$ for less. The isothermal line tendency is also well captured by simulations in all cases.

\subsection{Welding residual stresses estimation and HIC quantification}

The welding residual stresses in the WM and Heat Affected Zone (HAZ), as one of the central elements for the HIC, were estimated by the numerical simulation to be evaluated with the experimental results from the G-BOP test. Figure 10 exhibits the general panorama of the transverse residual stresses, most commonly analyzed in similar papers [12$16]$, for the three analyzed cases, allowing the observation of the greatest stress levels and variations are concentrated in the weld bead area.
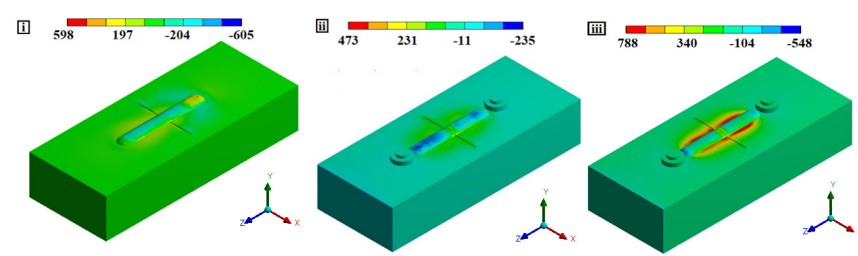

Fig. 10 General distribution of the transverse welding residual stresses for cases 1 (i), 2 (ii) and 3 (iii).

Figure 11 shows the variation of the normal stress in the three-axis of the system that appears in Figure 10, in the length the heat source had traveled to produce the longitudinal extension of the weld bead, in a line that passes through the geometric center of the weld metal cross-section. The normal stresses are the most critical for the HIC phenomena, because the paper they play during the hydrogen infiltration in the crystalline discontinuities, promoting the appearance and propagation of cracks. According to the observed stresses, it is clear that the G-BOP specimen geometric configuration, particularly in its gap, be it on the standard or in the modified test, establishes that the peak stresses, and also its steeper variations, occur in that area of interest where the specimen is broken. 


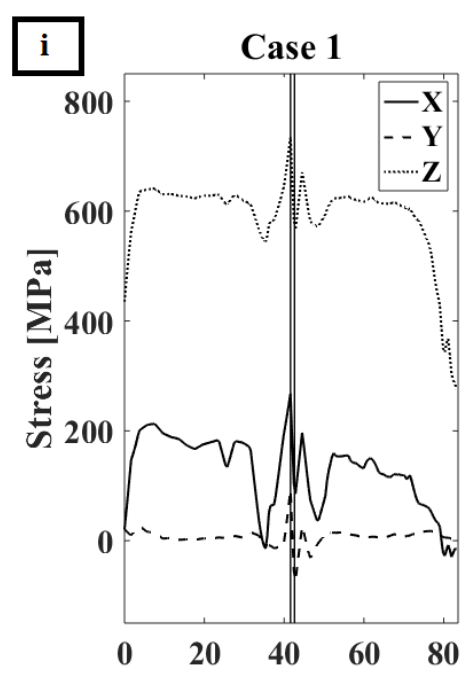

Case 2

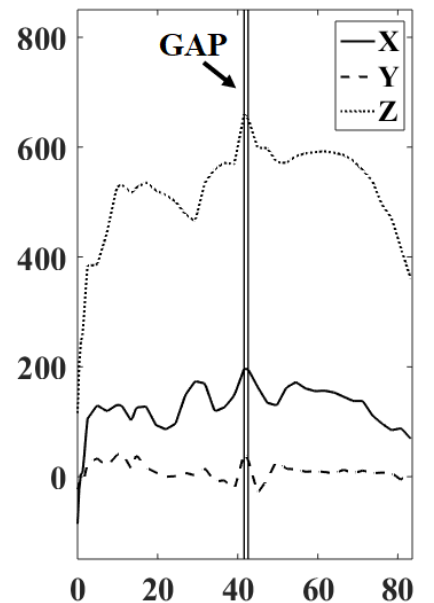

Case 3

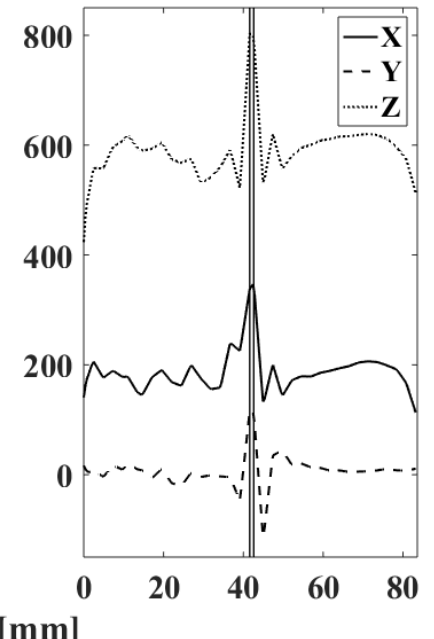

Position along the weld bead $[\mathrm{mm}]$
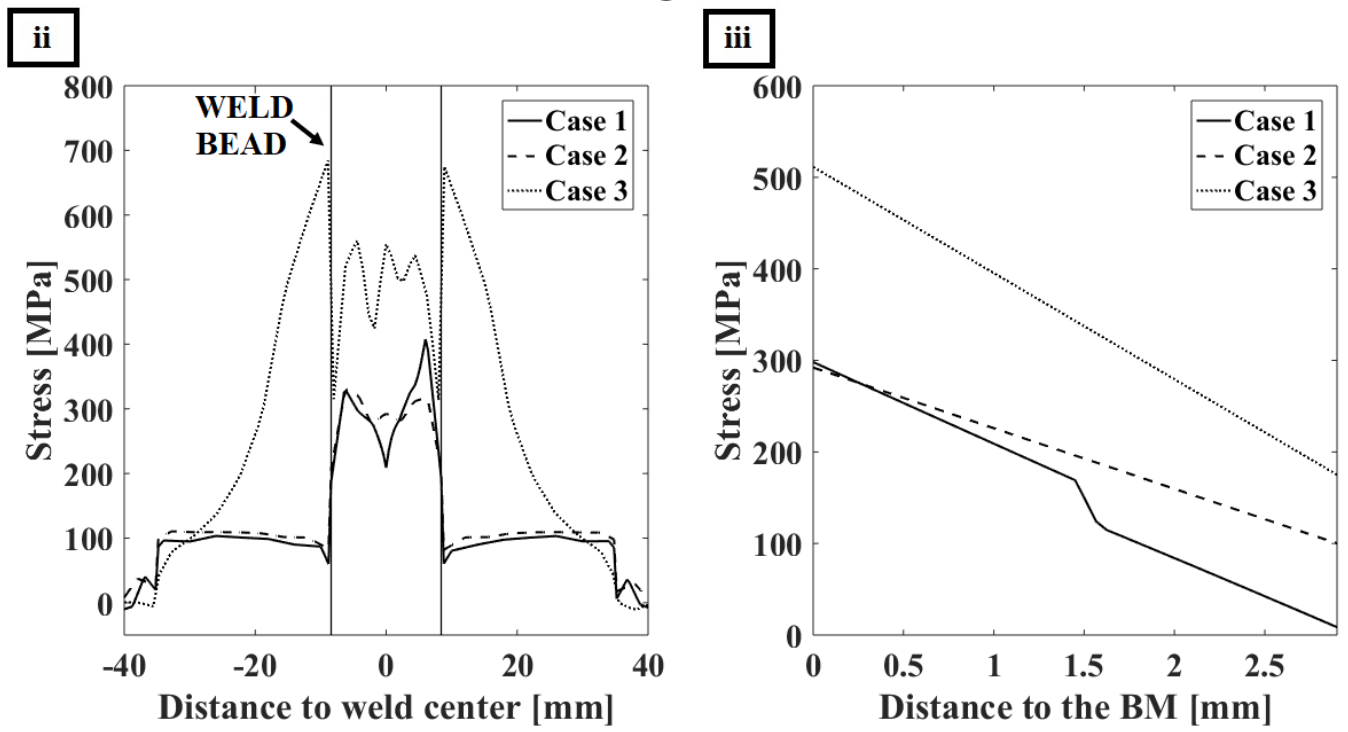

Fig. 11 Triaxial residual stresses across the weld bead length in its geometric center for the three cases (i), transverse residual stress profile through a transverse line crossing the BM and the WM on the gap area (ii), and transverse residual stress across the WM thickness in the middle of the gap, following the ascending sense (iii).

The item (ii) in Figure 11 presents the transverse residual stresses through a transverse line crossing the BM and WM, and also features the high-level stresses and the great variations that are present in the weld bead area. Finally, the graphic (iii) in Figure 11 displays the variation of the transverse residual stresses through WM thickness, establishing a compatibility relation between the fact that the residual stresses levels are decreasing from the bottom to the top of the WM, almost linearly, and the fact that the HIC generally occurs in the bottom area of the WM, as shown in Figure 12. Additionally, it is important to notice that the curves between cases 1 and 2 are very alike in shape and intensity, for all presented graphics, which corroborates that the modified configuration for the G-BOP test maintains the charac- teristics of the standard test regarding the welding residual stresses.

Figure 12 also represents the analysis process of the affected area by HIC through the heat tint produced during the test. The image vectorization makes it possible to quantify this effect, as shown in Table 2, which brings the results in terms of the percentage of the HIC affected area for three specimens from each of the three cases, its average values, and standard deviation.

The results in Table 2, if compared with the ones in Figure 11, shows agreement between the tests in case 1 and 2 , which are similar regarding the employed materials for $\mathrm{BM}$, but different in G-BOP test configuration. They present comparable levels of residual stresses in all graphics exhibited and no substantial variation between the HIC results. 

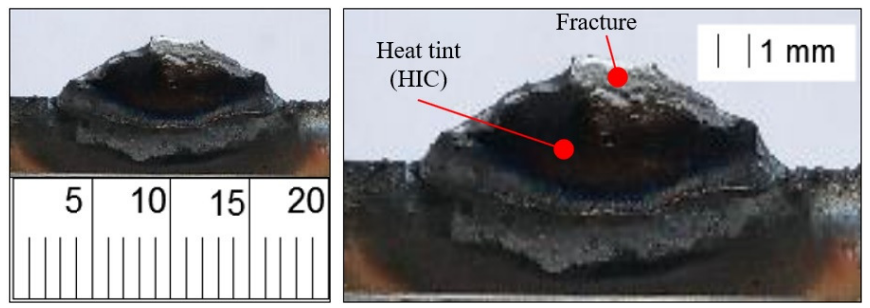

Fig. 12 HIC area representation.

Table 2 Percentage results of HIC affected areas for three specimens of each one of the three observed cases.

\begin{tabular}{|c|c|c|c|c|c|c|c|c|}
\hline \multicolumn{3}{|c|}{ Case 1} & \multicolumn{3}{|c|}{ Case 2} & \multicolumn{3}{|c|}{ Case 3} \\
\hline Test $1(\%)$ & Test $2(\%)$ & Test $3(\%)$ & Test $1(\%)$ & Test $2(\%)$ & Test $3(\%)$ & Test $1(\%)$ & Test $2(\%)$ & Test $3(\%)$ \\
\hline 66,7 & 20,0 & 41,7 & 23,2 & 17,2 & 50,2 & 25,1 & 74,9 & 43,1 \\
\hline \multicolumn{2}{|c|}{ Avg. value (\%) } & 42.8 & \multicolumn{2}{|c|}{ Avg. value (\%) } & 30.2 & \multicolumn{2}{|c|}{ Avg. value (\%) } & 47.7 \\
\hline \multicolumn{2}{|c|}{ Std. dev. (\%) } & 23.4 & \multicolumn{2}{|c|}{ Std. dev. (\%) } & 17.6 & \multicolumn{2}{|c|}{ Std. dev. (\%) } & 25.2 \\
\hline
\end{tabular}

Concerning case 3 , the obtained results show a great agreement with the expected for the modified G-BOP test, and observed for the previous cases. It solidifies the capability of the FEM to provide relevant information for the study of HIC, especially allied to the G-BOP test, and these results may eventually be extended to put up a correlation between the residual stresses and their influence in the HIC phenomena for this specific BM-WM pair, and any other.

\section{Conclusion}

The G-BOP test, for its inherent simplicity and practicality in HIC susceptibility evaluation, stands up as a fundamental tool for the referred phenomena investigation. The need to appropriately observe the WM behavior with its indicated BM added to the difficulty to find viable commercial plates of HSLA steels in the necessary thickness for the test, brought up the need for a test modification that, according to da Silva, Fals and Trevisan [7] and the present numericalexperimental results, allows a proper representation of the fundamental characteristics that confer the test the capacity to provide relevant information regarding HIC.

Among these characteristics, the similar thermal cycle and the concentration of stresses in the gap area, with similar behavior, are crucial, even though the levels depend, obviously, on the material properties of the utilized BM and WM. The pressure from the applied assembling torque in the bolts of the modified version of the test, in the levels indicated by the bolt manufacturer, being mostly employed for overcoming friction, induces low compressive stresses $(0.6 \mathrm{MPa})$ if compared with the observed after test, and, therefore, exerts low interference with test results. Beyond that, according to the numerical-experimental thermal results comparison, the appropriate roughness treatment of the contact surfaces makes the contact thermal resistance little expressive for the heat flux during welding, showing a low influence on the test accuracy.

For future work, the use of simulations to determine the optimal thickness for the WM in the modified G-BOP test, and to investigate the effects of thermal contact resistance variation, be it from changes in the contact pressure deriving from excessive torque application, or in the contact surface roughness, are interesting issues to be addressed.

Acknowledgements This work is financially supported by CNPq (Brazil) The Departments of Mechanical and Materials Engineering of the Universidade Federal da Paraíba (Brazil), with its many laboratories, provided all the structure needed for the production of the article.

\section{Declarations}

Funding: This work is financially supported by CNPq (Brazil). Conflicts of interest/Competing interests: The authors declare that they have no conflict of interest.

Availability of data and material: Not applicable.

Code availability: Not applicable.

Ethics approval: Not applicable.

Consent to participate: Not applicable.

Consent for publication: Not applicable.

Authors' contributions: Saulo M.A. Duarte is the main author, having contributed to the experimental analysis and writing of the article. Heitor A.S. Pereira contributed to the simulations and editing the article. José H.F. da Silva and Kelly C. Gomes served as supervisors. 


\section{References}

1. Tsuboi K, Yatabe H, Yamada K (1996) Hydrogen induced cracking in high strength steel. Mater Sci Technol 12:400-404. https://doi.org/10.1179/026708396790165876

2. Chakraborty G, Rejeesh R, Albert SK (2016) Study on hydrogen assisted cracking susceptibility of HSLA steel by implant test. Def Technol 12:490-495. https://doi.org/10.1016/j.dt.2016.09.003

3. Maroef I, Olson DL, Eberhart M, Edwards G R (2013) Hydrogen trapping in ferritic steel weld metal. Inter Mater Rev 47:191-223. https://doi.org/10.1179/095066002225006548

4. Hu J, Yang J, Fang H et al (2006) Numerical simulation on temperature and stress fields of welding with weaving. Sci Technol Weld Joi 11:358-365. https://doi.org/10.1179/174329306X124189

5. Yurioka N, Suzuki H (1990) Hydrogen assisted cracking in CMn and low alloy steel weldments. Int Mater Rev 35:217-249. https://doi.org/10.1179/imr.1990.35.1.217

6. Graville BA, McParlan M (1974) Weld-metal cold cracking. Met Constr Br Weld J 6:62-63

7. da Silva JHF, Fals HC, Trevisan RE (2008) Proposal of a New GBOP Test to Evaluate Cracks in Weld Beads in Thin Sheets. J Fail Anal Prev 9:74-80. https://doi.org/10.1007/s11668-008-9199-5

8. Attarha MJ, Sattari-Far I (2011) Study on welding temperature distribution in thin welded plate through experimental measurements and finite element simulation. J Mater Process Technol 211:688-694. https://doi.org/10.1016/j.jmatprotec.2010.12.003.

9. Negi V, Chattopadhyaya S (2013) Critical Assessment of Temperature Distribution in Submerged Arc Welding Process. Adv Mater Sci Eng. https://doi.org/10.1155/2013/543594

10. Chen Y, He Y, Chen $\mathrm{H}$ et al (2014) Effect of weave frequency and amplitude on temperature field in weaving welding process. Int J Adv Manuf Technol 75:803-813. https://doi.org/10.1007/s00170014-6157-0

11. Pereira HAS, Rodrigues MC, Firmino JVLC (2019) Implementation of weave patterns by path parameterization in the simulation of welding processes by the finite element method. Int J Adv Manuf Technol 104:477-487. https://doi.org/10.1007/s00170-019-03861-5

12. Cañas J, Picón R, Pariís F et al (1996) A simplified numerical analysis of residual stresses in aluminum welded plates. Comput Struct 58:59-69. https://doi.org/10.1016/0045-7949(95)00112-T

13. Deng D, Murakawa H (2006) Numerical simulation of temperature field and residual stress in multi-pass welds in stainless steel pipe and comparison with experimental measurements. Comput Mater Sci 37:269-277. https://doi.org/10.1016/j.commatsci.2005.07.007

14. Deng D, Murakawa H (2008) Prediction of welding distortion and residual stress in a thin plate butt-welded joint. Comput Mater Sci 43:353-365. https://doi.org/10.1016/j.commatsci.2007.12.006

15. Deng D, Murakawa H (2008) FEM prediction of buckling distortion induced by welding in thin plate panel structures. Comput Mater Sci 43:591-607

16. Chang K, Lee C, Park KT et al (2010) Analysis of Residual Stress in Stainless Steel Pipe Weld Subject to Mechanical Axial Tension Loading. Int J Steel Struct 4:411-418. https://doi.org/10.1007/BF03215848

17. Atkins G, Thiessen D, Nissley N et al (2002) Welding process effects in weldability testing of steel. Weld J 11:61-68

18. Teng TL, Chang PH, Tseng WC (2003) Effect of welding sequences on residual stresses. Comput Struct 81:273-286. https://doi.org/10.1016/S0045-7949(02)00447-9

19. Nóbrega JA et al (2016) Numerical Evaluation of Temperature Field and Residual Stresses in an API 5L X80 Steel Welded Joint Using the Finite Element Method. Met. https://doi.org/10.3390/met6020028

20. Goldak J, Chakravarti A, Bibby M (1984) A new finite element model for welding heat sources, Metall Trans B 15B:299-305

21. Kern D Q (1965) Process Heat Transfer. McGraw-Hill, New York
22. Budynas R, Nisbett J, Shigley J (2011) Shigley's mechanical engineering design. McGraw-Hill, Chicago

23. Yovanovich M, Marotta E (2003) Thermal spreading and contact resistances. In: Bejan A, Kraus AD (ed) Heat Transfer Handbook, Wiley, New Jersey, pp 261-393 
Figures
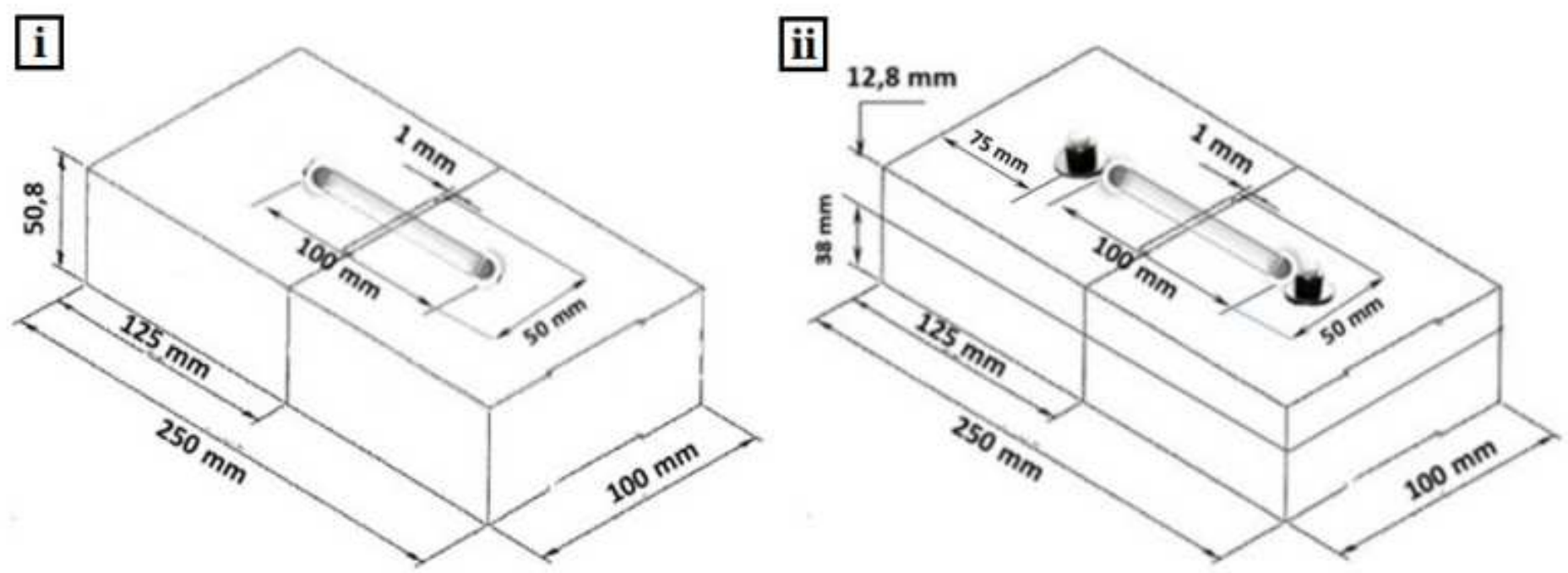

Figure 1

Standard (i) and Modified (ii) G-BOP test specimen.
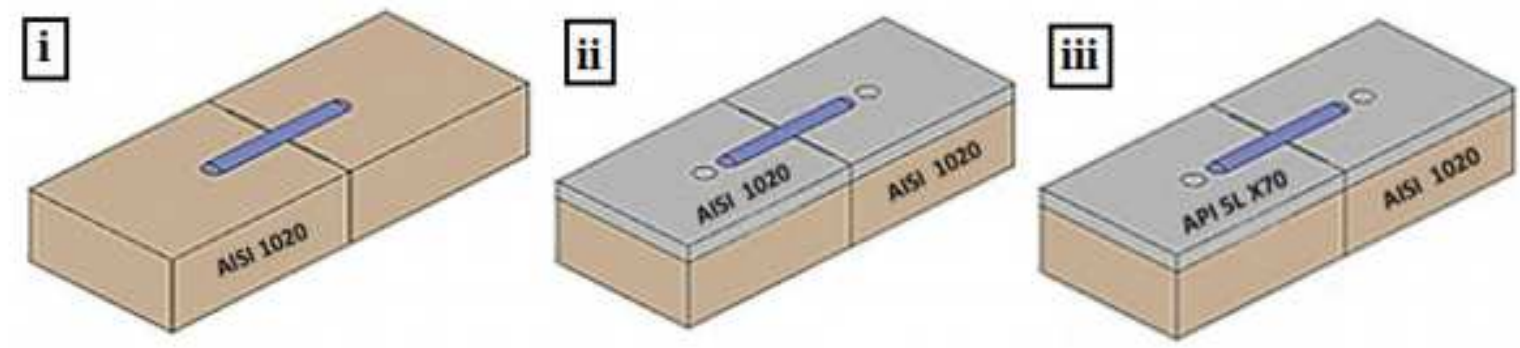

Figure 2

Schematic representation of the cases 1 (i), 2 (ii) and 3 (iii). 

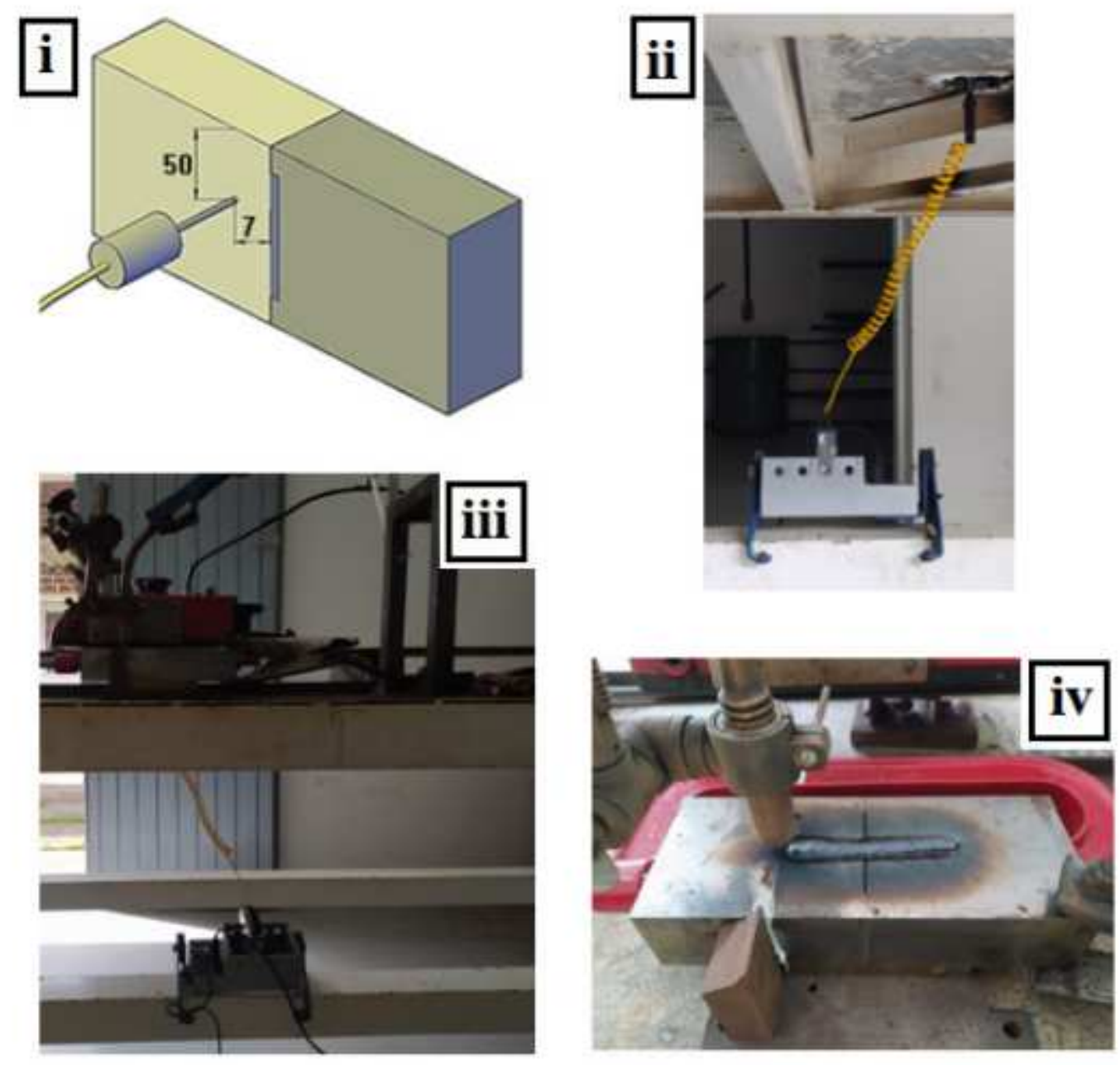

Figure 3

Position of the thermocouple (i), real measuring device arrangement (ii), automatic welding mechanism (iii) and welded specimen (iv).
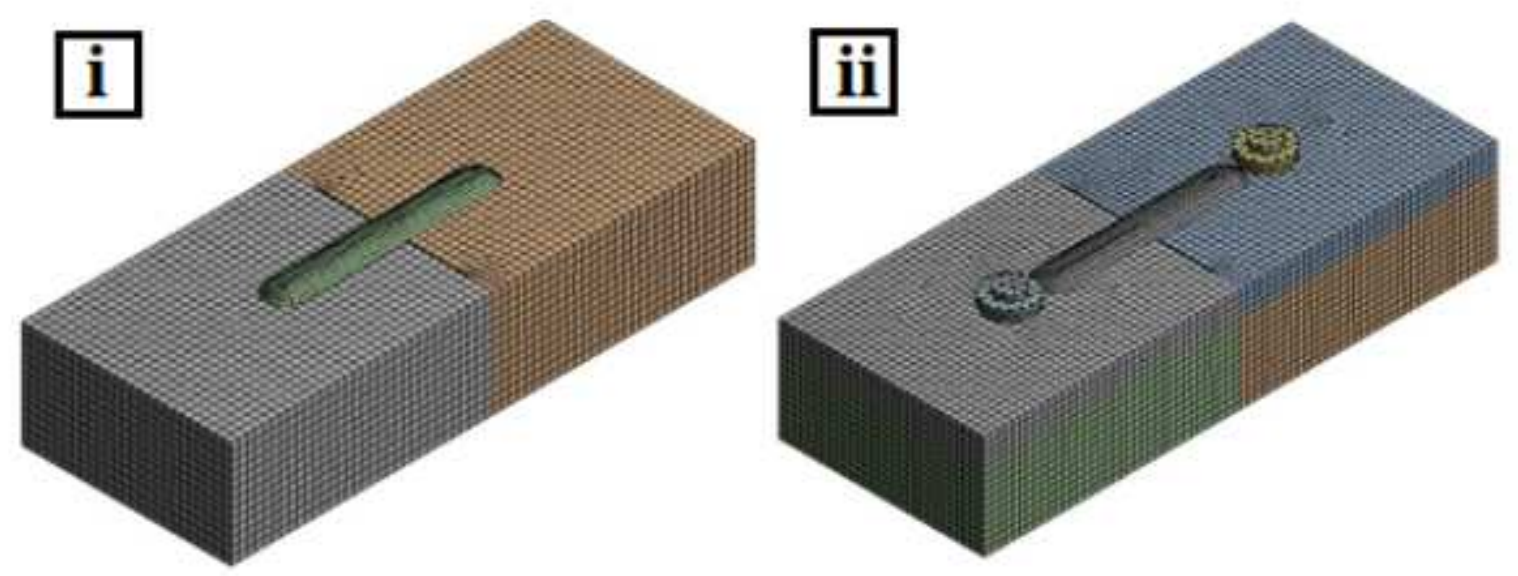

Figure 4 
FEM mesh for standard (i) and modified (ii) G-BOP specimens.
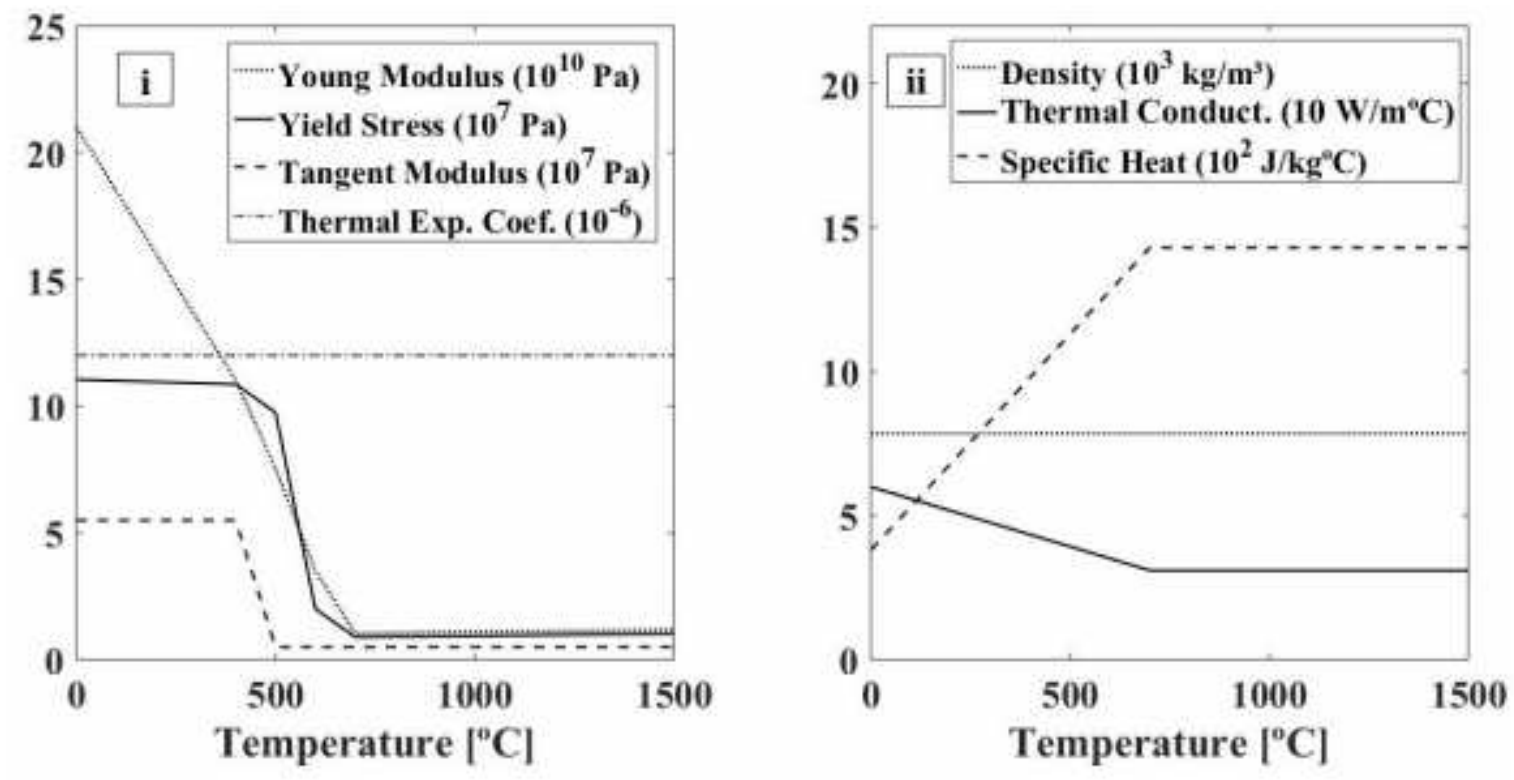

Figure 5

AISI 1020 steel thermal (i) and mechanical (ii) properties [18].
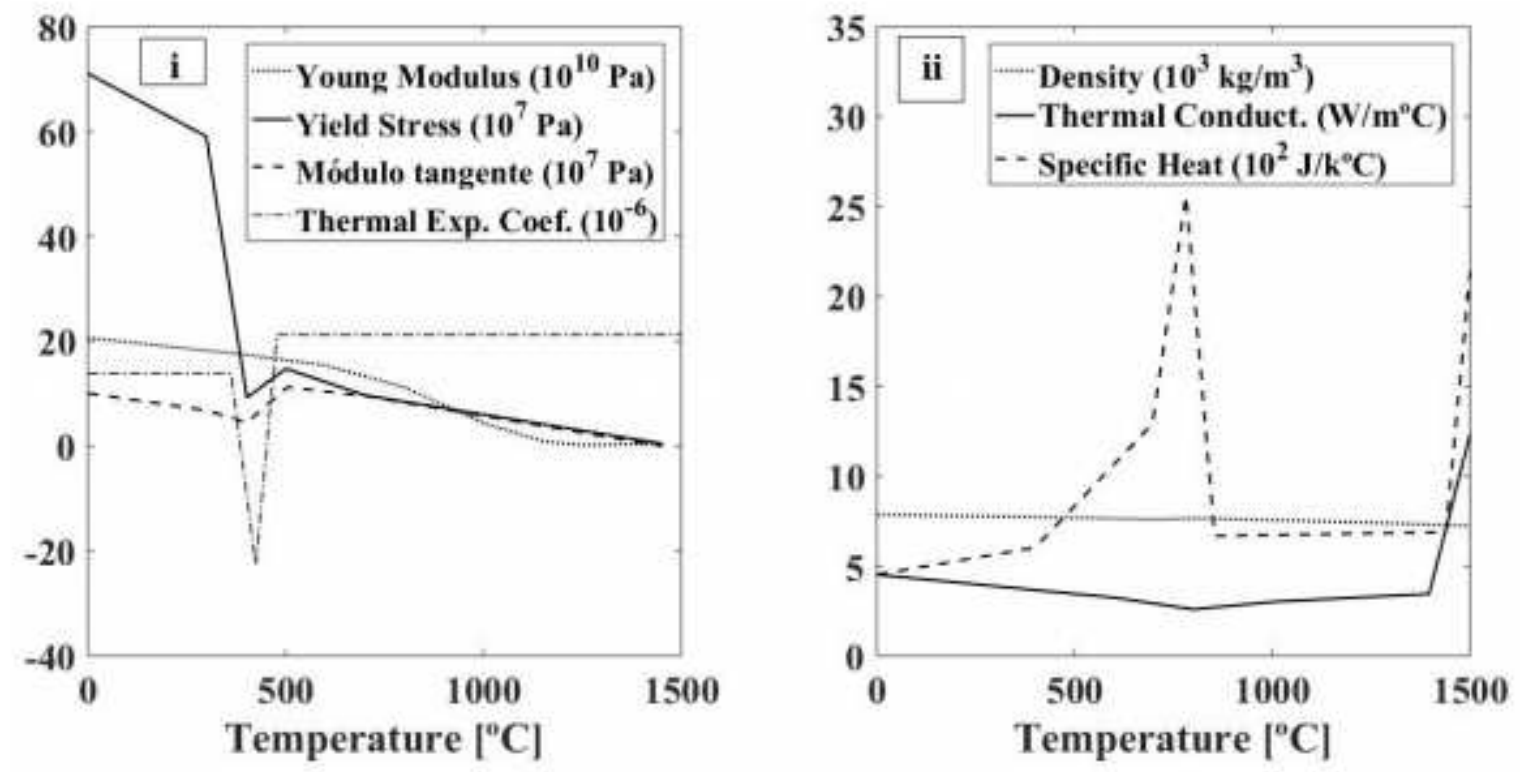

Figure 6

API 5L X70 thermal (i) and mechanical (ii) properties [19]. 

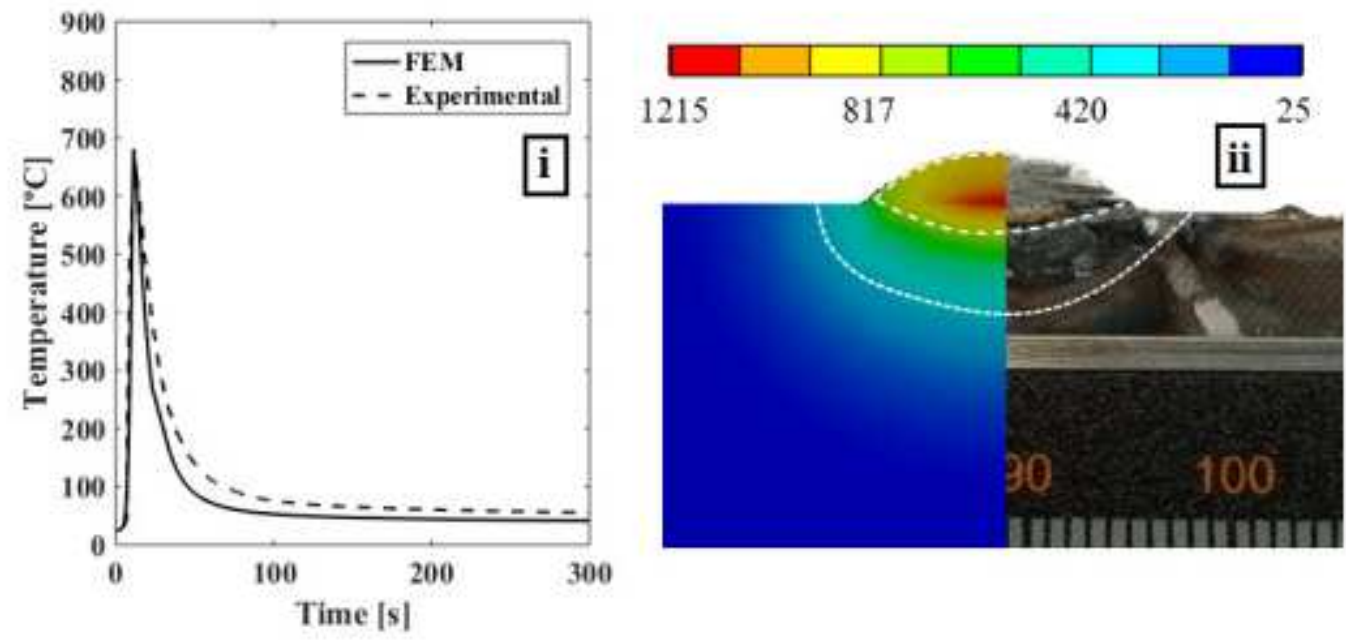

Figure 7

Numerical-experimental comparison of the thermal cycle in the thermocouple position (i) and of the weld bead cross-section (ii) for standard G-BOP test in case 1.
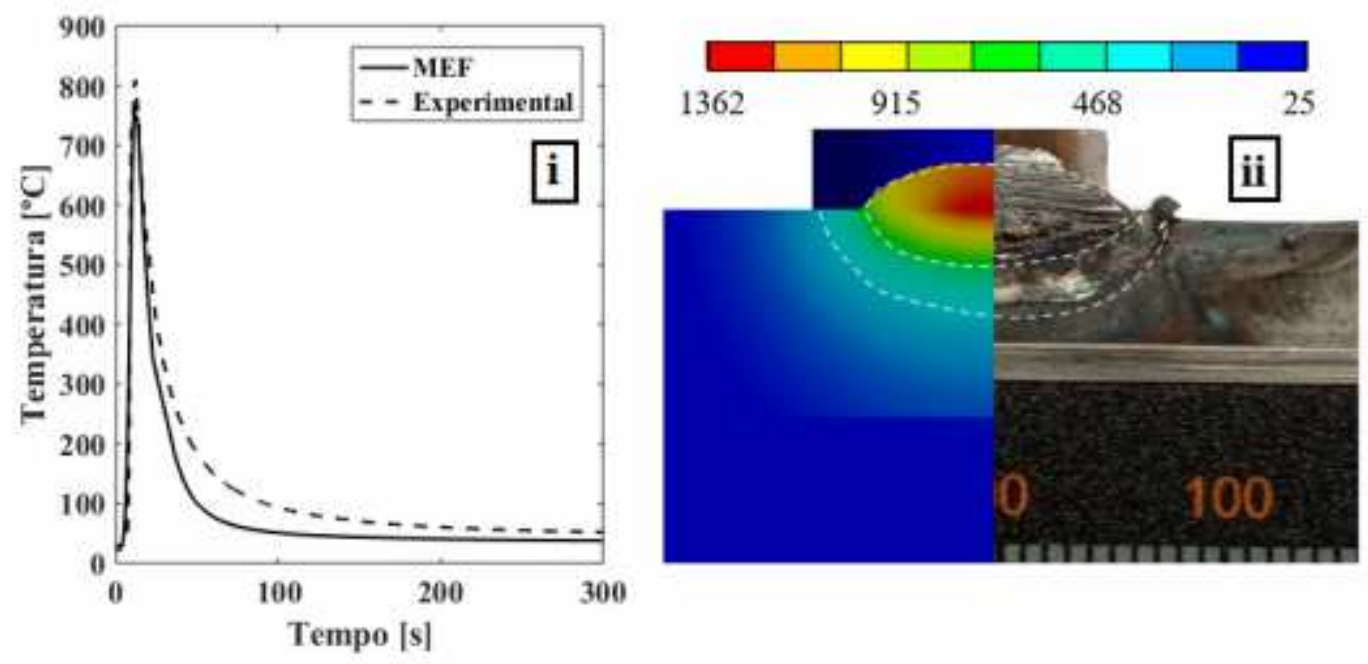

Figure 8

Numerical-experimental comparison of the thermal cycle in the thermocouple position (i) and of the weld bead cross-section (ii) for the modified G-BOP test in case 2 . 

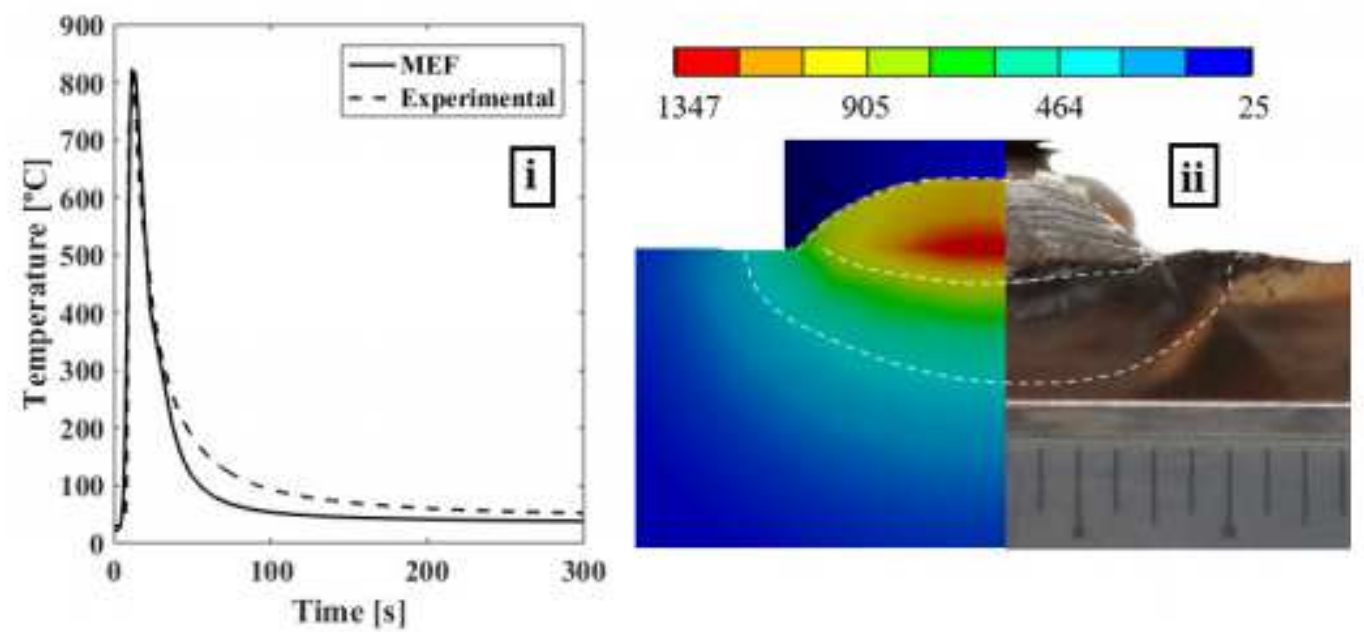

\section{Figure 9}

Numerical-experimental comparison of the thermal cycle in the thermocouple position (i) and of the weld bead cross-section (ii) for modified G-BOP test in case 3.
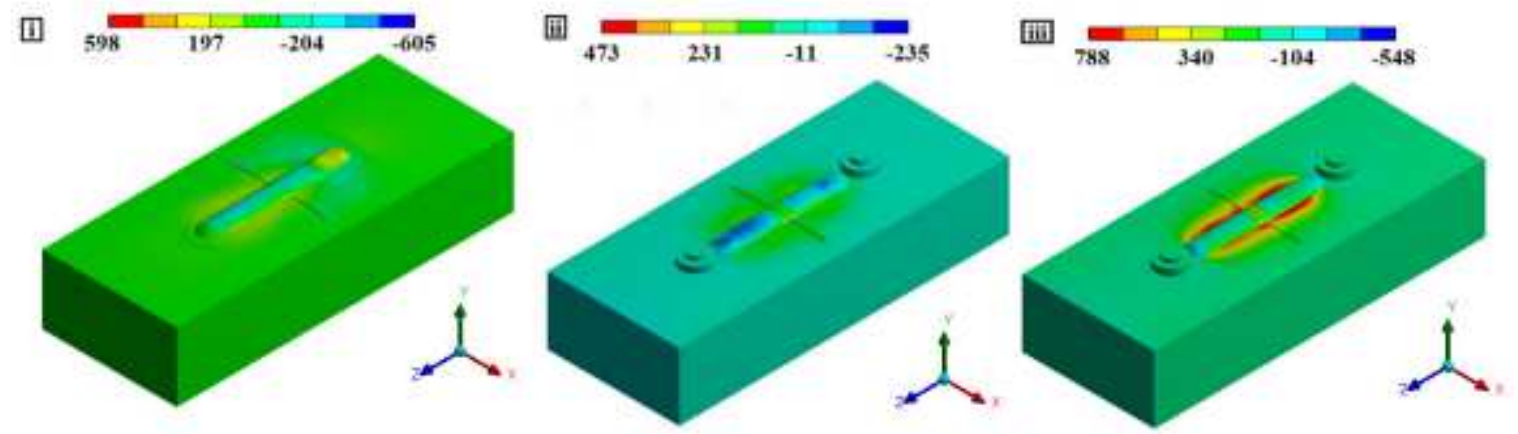

Figure 10

General distribution of the transverse welding residual stresses for cases 1 (i), 2 (ii) and 3 (iii). 

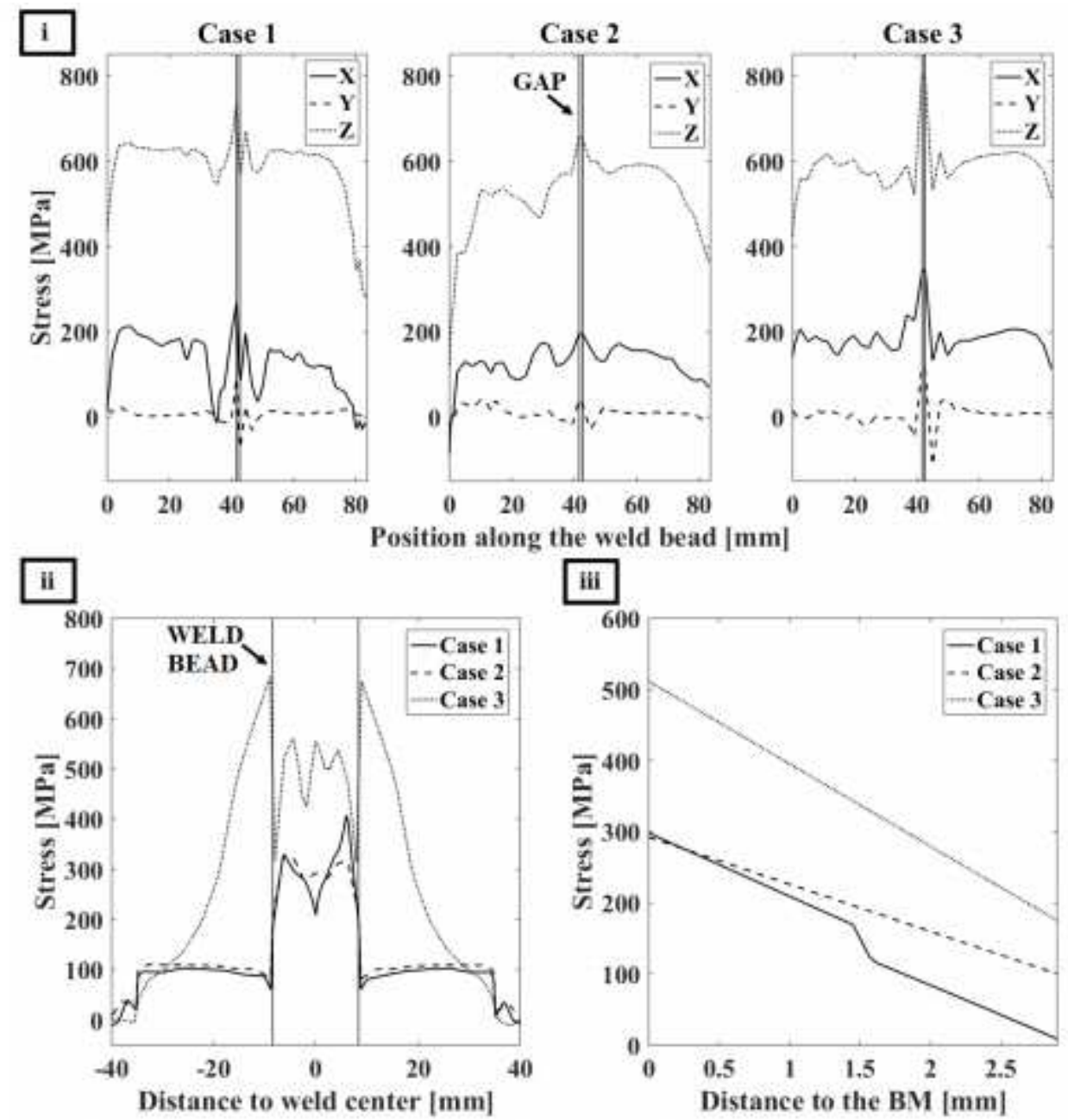

\section{Figure 11}

Triaxial residual stresses across the weld bead length in its geometric center for the three cases (i), transverse residual stress profile through a transverse line crossing the BM and the WM on the gap area (ii), and transverse residual stress across the WM thickness in the middle of the gap, following the ascending sense (iii).
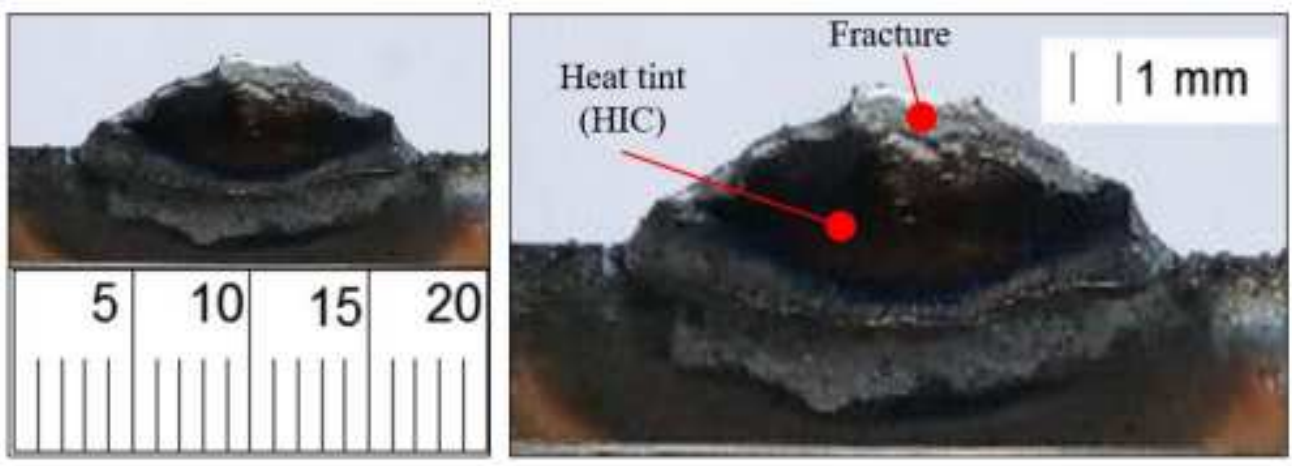

\section{Figure 12}

HIC area representation. 